\title{
The relative benefit of word context is a constant proportion of letter identification time
}

\author{
ELISABETH M. FINE \\ Harvard Medical School, Boston, Massachusetts
}

\begin{abstract}
Letter identification is reduced when the target letter is surrounded by other, flanking letters. This visual crowding is known to be impacted by physical changes to the target and flanks, such as spatial frequency content, polarity, and interletter spacing. There is also evidence that visual crowding is reduced when the flanking letters and the target letter form a word. The research reported here investigated whether these two phenomena are independent of each other or whether the degree of visual crowding impacts the benefit of word context. Stimulus duration thresholds for letters presented alone and for the middle letters of 3-letter words and nonwords were determined for stimuli presented at the fovea and at the periphery. In Experiment 1, the benefit of word context was found to be the same at the fovea, where visual crowding is minimal, and at the periphery, where visual crowding is substantial. In Experiment 2, visual crowding was manipulated by changing the interletter spacing. Here, too, the benefit of word context was fairly constant for the two retinal locations (fovea or periphery), as well as with changes in interletter spacing. These data call into question both the idea that the benefit of word context is greater when stimulus quality is reduced (as is the case with visual crowding) and the idea that words are processed more effectively when they are presented at the fovea.
\end{abstract}

Lateral masking refers to the reduced perceptibility of visual stimuli when they are surrounded by other, nearby stimuli. Visual crowding is a form of lateral masking that refers specifically to the reduced perceptibility of letters when they are surrounded by other letters (Chung, Levi, \& Legge, 2001). Although this definition of crowding is by no means universal (e.g., Cavanagh, 2001; Intriligator \& Cavanagh, 2001; Leat, Li, \& Epp, 1999; Tripathy \& Cavanagh, 2002), it is the one adopted here. Understanding how the perceptibility of letters changes when they are surrounded by other letters is critical to our understanding of such tasks as reading (Bouma, 1970), where the letters that make up words must be identified.

Most studies of visual crowding (and lateral masking) have focused on understanding how physical changes to the stimulus, such as spatial frequency content, polarity, or flank-to-target distance (among other things), modulate the degree of visual crowding. In a previous study, I

Portions of these data were reported at the 2000 Mini-Conference on Visual Perception and Attention, Washington, DC. This research was supported in part by donations from the William Randolph Hearst Foundation and the Joseph E. and Marjorie B. Jones Foundation. Thanks to Cathleen Moore and Adam Reeves for their comments on an earlier version of this article. This article has benefited greatly from the reviews of Anke Huckauf, Kenneth Paap, and an anonymous reviewer. I also thank Douglas Goger and Gayle Añonuevo for their help with data collection. Correspondence concerning this article should be addressed to E. M. Fine, Schepens Eye Research Institute and Harvard Medical School, 20 Staniford Street, Boston, MA 02114 (e-mail: fine@vision.eri.harvard.edu).

Note-This article was accepted by the previous editorial team, headed by Neil Macmillan. looked at the semantic relationship between the surrounding letters (the flanks) and the target letter (Fine, 2001). In that study, the middle letters of 3-letter words, 3-letter nonwords, and letters flanked by one $x$ on each side (xax) were presented at $10^{\circ}$ eccentricity. Observers were about $12 \%$ more accurate in identifying the middle letters of words than they were in identifying the middle letters of nonwords or letters flanked by $x$ s.

These data extend the findings of many others that letters are recognized more easily when they are part of a word than when they are surrounded by letters that do not form a word. In Reicher's (1969) original study of the "word superiority effect," observers made a two-alternative forced choice discrimination between letters that were presented as part of a 4-letter word, as part of a 4-letter nonword (the letters of the words were randomized, except in the critical location), and as single letters. The stimuli were selected so that either of two letters in the same location would form words (e.g., word vs. work). He found that letter identification was better when the four letters formed a word than when they did not or when the target letter was presented alone. Wheeler (1970) expanded on Reicher's paradigm to test hypotheses regarding spatial uncertainty (within the word and the display) and added to the compelling evidence that perceptual units within words are larger than single letters and that multiple letters interact to improve letter identification in words.

Thus, in addition to inhibiting letter identification (Bouma, 1970, 1973; Fine, 2001; Jacobs, 1979), flanking letters can also facilitate letter identification. The question asked in the present experiments is whether or not 
these two factors are independent. Specifically, do manipulations that are known to change the degree of visual crowding similarly change the benefit of word context.

Although visual crowding can occur at the fovea (see Flom, Weymouth, \& Kahneman, 1963, and Jacobs, 1979, among others), it has a far greater impact at the retinal periphery (Flom, 1991; Flom et al., 1963; Huckauf, Heller, \& Nazir, 1999; Jacobs, 1979; Latham \& Whitaker, 1996; Nazir, 1992; Strasburger, Harvey, \& Rentschler, 1991). In the study mentioned above (Fine, 2001), changes in letter identification accuracy were looked at only at the periphery, where visual crowding is more pronounced. To my knowledge, all of the studies in which the benefits of word context on letter identification have been investigated have presented the stimuli at or near the fovea. Thus, it is possible that the benefit of word context may differ at the fovea and the periphery, where visual crowding also differs.

There are many data that suggest that when the quality of the visual stimulus is reduced (as it is with visual crowding; Fine, 2003a), context plays a larger role. For example, in Massaro and Cohen's (1994) fuzzy logical model of perception (FLMP), there is a tradeoff between stimulus quality and the effect of context, such that word context has a greater impact on letter identification when the stimulus quality is reduced. This suggests that word context should have a greater benefit when stimuli are presented at the retinal periphery than when they are presented at the fovea.

It has also been argued that words are read more effectively when they are presented at the fovea than when they are presented at the periphery (Chaparro \& Young, 1993; Ferguson, 1993; Rayner \& Bertera, 1979). For example, Chaparro and Young compared word identification, using just rods and just cones, at $0^{\circ}, 5^{\circ}, 10^{\circ}, 15^{\circ}$, and $20^{\circ}$ below fixation. Letter size was the same at all locations. As one would expect, both naming speed and accuracy decreased with eccentricity. However, they found no qualitative differences in the patterns of results on the basis of which photoreceptor was isolated. From these data, they inferred that the pattern recognition necessary for reading was optimal at or near the fovea and that this was independent of variations in photoreceptor density or resolution across the visual field.

Thus, Massaro and Cohen's (1994) model predicts greater word benefit in the periphery because stimulus quality is reduced, whereas the work of Chaparro and Young (1993) suggests that there will be a greater word benefit at the fovea. It is also possible that, like the benefit of sentence context on reading lists of words, there will be no difference in performance between the fovea and the periphery (Fine, Hazel, Petre, \& Rubin, 1999; Fine \& Peli, 1996).

\section{EXPERIMENT 1}

The stimulus duration (SD) thresholds necessary to identify single letters and the middle letters of 3-letter words and trigrams presented at the fovea and at the pe- riphery were used to determine the impact of visual crowding and word context on letter identification. Threshold SD was chosen as the dependent measure because pilot testing indicated that SDs for which above-chance performance was possible at the periphery lead to perfect performance at the fovea. This was true even though we scaled the letters at the periphery so that they were of approximately equal visibility to letters in the fovea (Farrell \& Desmarais, 1990). Although SD threshold is an unusual method for determining visual crowding, it may be better than the typical method of measuring percentage correct for a fixed SD. In a recent study in which SD was varied, Tripathy and Cavanagh (2002) found different degrees of crowding, depending on SD. In their study, the change in $\mathrm{SD}$ was used to equate performances for individual targets. Only in their post hoc analysis did they discover that SD had a profound impact on visual crowding. When SD was specifically manipulated (Fine, 2003b), Tripathy and Cavanagh's finding was confirmed - visual crowding does vary with SD. Therefore, finding the SD required to obtain a fixed (threshold) level of performance may be a cleaner measure of visual crowding.

\section{Method}

Observers. Twelve observers with self-reported normal or corrected-to-normal vision participated in this experiment. This and the following experiment were approved by the Institutional Review Board of the Schepens Eye Research Institute. Informed consent was obtained from all the observers, and they were compensated for their time.

Apparatus. Stimuli were presented on a 17-in. Sony Multiscan 200 ES monitor set at $75 \mathrm{~Hz}$ and $832 \times 624$ pixel resolution. Stimulus presentation was controlled using RSVP software (Williams \& Tarr, RSVP 4.03; http//psych.umb.edu/rsvp/) running under System 8.6 on a Mac G3 computer.

Stimuli. The stimuli were 3-letter words, nonword trigrams, and letters; all were formed using lowercase Courier font. This font was chosen because it is fixed width (monospaced) and, therefore, interletter spacing (center-to-center) is constant (this was especially important for the next experiment, where interletter spacing was manipulated). The 3-letter words were drawn from the Francis and Kučera (1982) word norms and the Scrabble 3-letter word list. Target letters were selected so that there were at least 3 familiar words with the same middle letter. No attempt was made to control for familiarity or frequency. Nineteen stimulus letters were chosen. The stimuli used are included in the Appendix. The middle letter of each of the words was changed to form the trigrams so that (1) all 3 words with the same middle letter had the same letter substitute, (2) the new letter did not create a 3-letter word for any of the 3 base words, and (3) the new letter was of approximately the same shape (e.g., letters with ascenders replaced letters with ascenders). The single letters were the original 19 letters, each displayed three times. The target letters in the trigrams were 14 of the letters used for the 3-letter words and 5 additional letters. In other experiments in this lab (including other experiments on visual crowding), we have found no difference in the visibility of the letters that differed between sets of stimuli. There were 57 words +57 trigrams +57 letters, for a total of a 171 trials per condition.

The letters were scaled so that they were approximately the same size relative to predicted acuity threshold at the fovea and at $10^{\circ} \mathrm{ec}-$ centricity (Farrell \& Desmarais, 1990). Letters presented at the fovea were $0.4^{\circ} \times 0.4^{\circ}$. Letters presented at the periphery were $1.3^{\circ} \times 1.1^{\circ}$.

Design and Procedure. The observers reported the middle letter of the 3-letter sequences or the letter presented alone. The stim- 
uli were always on the horizontal meridian, and the middle letter was either at fixation or $10^{\circ}$ to the right or left of fixation. Target presentation at the fovea or the periphery was blocked, and the order alternated across observers. The 12 observers were separated into two groups. The observers in the first group were presented with the stimuli in blocks. For this group, order of stimulus type was randomized and was the same at the fovea and at the periphery. For the second group of observers, the stimulus type was semirandom. The

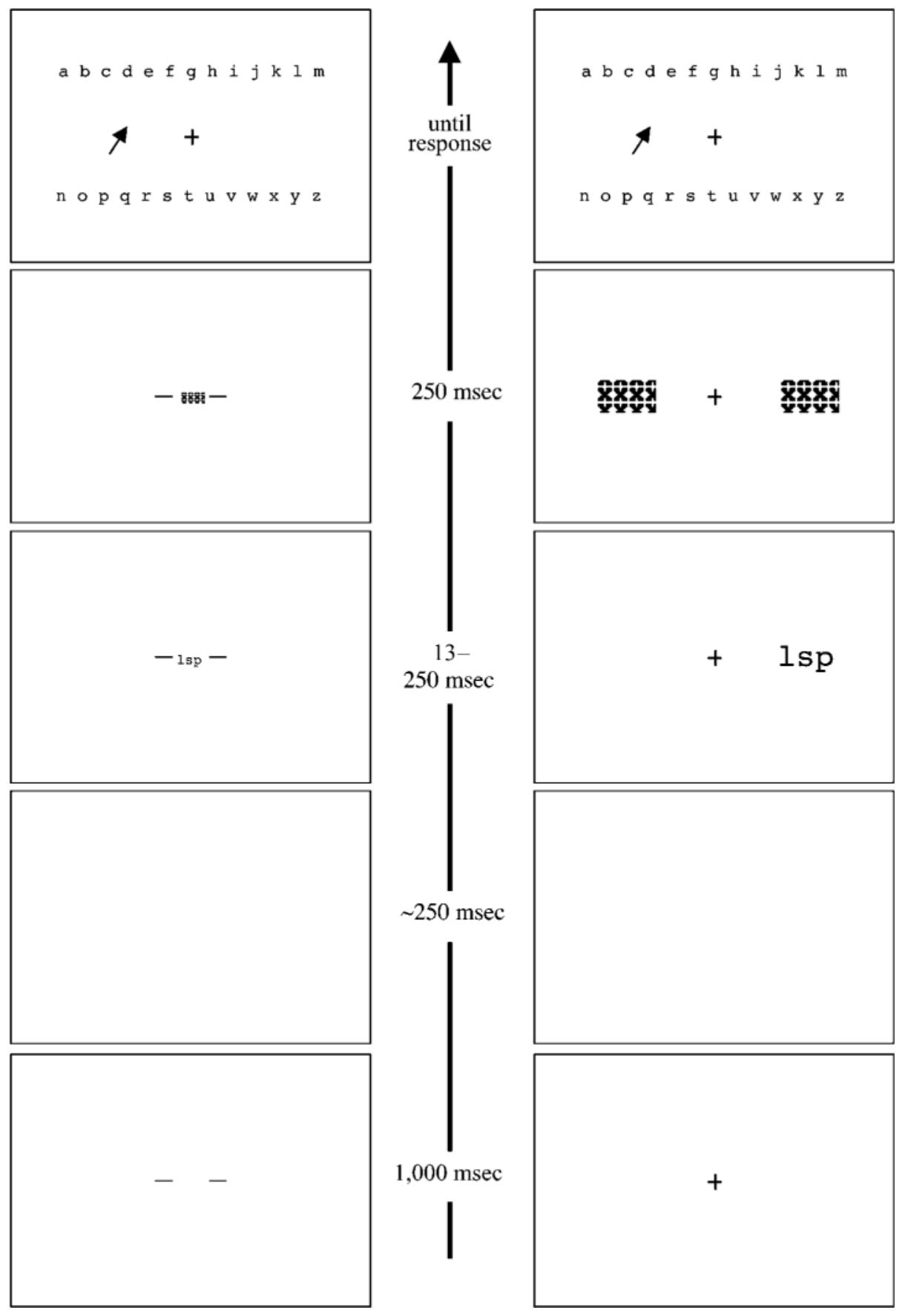

Figure 1. Stimulus display for Experiment 1. The trial runs from the bottom of the figure to the top. The left panel shows trials at the fovea, and the right panel shows trials at the periphery. A fixation marker is followed by a blank screen (to sync with the vertical refresh of the monitor), and then the stimulus is displayed for a variable stimulus duration and then masked. The response matrix follows immediately after the mask. The observer's task is to click on the letter that matches the target. The stimulus display for Experiment 2 was the same, except that the masks were wider to accommodate the increased space between letters. 
single letters were always presented in a single block, either before or after a block of randomized words and trigrams.

Figure 1 shows a typical trial sequence. The trial runs from the bottom to the top of the figure. Trials presented at the fovea are shown on the left, and trials presented at the periphery on the right. As is shown in the bottom row, each trial began with a fixation marker (two $1.3^{\circ}$ lines separated by $4^{\circ}$ for trials at the fovea or a $1.3^{\circ} \times 1.3^{\circ}$ cross for trials at the periphery), which appeared for $1,000 \mathrm{msec}$. This was followed by a blank screen for $250 \mathrm{msec}$ and, after a random delay of $0-13 \mathrm{msec}$ (to allow the display to sync with the vertical refresh), by the stimulus for a duration determined by a staircase (middle row). Following the stimulus display, a mask appeared for $250 \mathrm{msec}$ (fourth row), followed immediately by the response matrix (top row). For the fovea, the stimulus was always centered at fixation, between the two fixation lines. For the periphery, the stimuli were randomly presented to either the right or the left of fixation (a trial to the right is shown in the figure), to reduce the likelihood of the observers' moving their eyes toward the stimulus. The mask was rows of alternating black and white $x \mathrm{~s}$. It was $1.6^{\circ} \times$ $0.9^{\circ}$ at the fovea and $4.8^{\circ} \times 3.0^{\circ}$ at the periphery, large enough to mask the area of the 3-letter sequences. When the stimuli were presented at the periphery, both possible stimulus locations were masked. The response matrix consisted of all 26 letters of the alphabet, presented on two lines of 13 letters each, one above and one below the fixation marker (top row of Figure 1). The observers responded by clicking on the letter they saw presented either alone or in the middle of the 3-letter sequence. This recorded their response and restarted the trial sequence. The observers were instructed to guess if they were unsure, and a response was required on every trial. The observers were reminded before each block of trials to move their eyes back to fixation before pressing the mouse button. Responses were not timed. Data collection required about $20 \mathrm{~min}$.

The observers were given breaks between blocks of trials (the mixed block of words and trigrams was presented in two parts, with a break in between) and were encouraged to take other breaks when needed. By pointing to the response without clicking the mouse, trial execution was halted.

For each stimulus type, the staircase started at $133 \mathrm{msec}$. The first correct response decreased the SD by $27 \mathrm{msec}$ (twice the frame rate of the monitor), and the first incorrect response increased the $\mathrm{SD}$ by $53 \mathrm{msec}$. After the second reversal, step size was halved in each direction. This one-up, one-down staircase with unequal step size results in about 78\% correct responses (García-Pérez, 1998; Kaernbach, 1991). The staircase was modified so that it never fell below the frame rate of the monitor $(13 \mathrm{msec})$ or above $250 \mathrm{msec}$. The upper limit was imposed to limit the impact of possible eye movements to the stimulus.

Before data collection began, the observers were presented with 12 practice trials presented at a constant SD. The first 6 practice trials were presented for $500 \mathrm{msec}$, and the remaining trials for $120 \mathrm{msec}$.

\section{Results}

The first two reversals were eliminated. The remaining reversals were averaged to determine the threshold SD. The average number of reversals was $25.7 \pm 0.70$ (mean $\pm S E M$ ) in the fovea and $24.6 \pm 0.86$ in the periphery, a nonsignificant difference.

Threshold SDs were submitted to a 2 (group: blocked or random) $\times 2$ (location: fovea or periphery) $\times 3$ (stimulus type: letters, trigrams, or words) mixed-model analysis of variance (ANOVA). There was no main effect of group $[F(1,10)<1$, n.s. $]$, nor did group interact with any of the remaining variables [all $F_{\mathrm{s}}<1$ ]. Therefore, the data were collapsed across group in the subsequent analyses. SD thresholds are shown in Table 1.

As was indicated in the Method section, the size of the letters was scaled so that the stimuli presented at the fovea and the periphery were of approximately the same size, relative to the predicted acuity threshold at each location. A comparison of threshold SDs for the singleletter stimuli showed that SD thresholds averaged $4.1 \pm$ $2.4 \mathrm{msec}$ shorter when the letters were presented at the fovea than when they were presented at the periphery, a nonsignificant difference $[t(11)=2.7, p=.116]$. The difference in threshold SD between the fovea and the periphery ranged from $8.7 \mathrm{msec}$ faster at the periphery to $20.0 \mathrm{msec}$ slower across observers. A 2 (location) $\times 3$ (stimulus type: letters, words, or trigrams) ANOVA on the threshold SDs showed significant effects of location

Table 1

Mean Stimulus Duration Thresholds ( \pm SEM Across Observers) and Difference in Thresholds for Each Stimulus Type by Experiment and Condition

\begin{tabular}{|c|c|c|c|c|c|c|}
\hline \multirow[b]{2}{*}{ Condition } & \multicolumn{3}{|c|}{ Stimulus } & \multicolumn{3}{|c|}{ Comparison } \\
\hline & Letters (L) & Words (W) & Trigrams $(\mathrm{T})$ & W-L & T-L & $\mathrm{T}-\mathrm{W}$ \\
\hline \multicolumn{7}{|l|}{ Experiment 1} \\
\hline Fovea & $32.9 \pm 1.2$ & $32.3 \pm 0.9$ & $44.7 \pm 9.8$ & $-0.6 \pm 1.2$ & $11.8 \pm 2.2$ & $12.4 \pm 2.7$ \\
\hline Periphery & $37.0 \pm 2.2$ & $148.8 \pm 18.2$ & $193.3 \pm 12.5$ & $111.8 \pm 17.3$ & $156.3 \pm 12.0$ & $44.5 \pm 9.8$ \\
\hline \multicolumn{7}{|l|}{ Experiment 2} \\
\hline Fovea & $32.8 \pm 1.3$ & & & & & \\
\hline Periphery & $36.8 \pm 1.5$ & & & & & \\
\hline \multicolumn{7}{|l|}{0 space } \\
\hline Fovea & & $39.6 \pm 13.0$ & $64.6 \pm 7.7$ & $6.7 \pm 2.5$ & $31.8 \pm 7.4$ & $25.0 \pm 6.3$ \\
\hline Periphery & & $132.8 \pm 12.5$ & $174.7 \pm 10.1$ & $96.0 \pm 11.7$ & $137.9 \pm 9.8$ & $41.9 \pm 8.7$ \\
\hline \multicolumn{7}{|l|}{1 space } \\
\hline Fovea & & $32.9 \pm 1.4$ & $41.2 \pm 2.4$ & $0.1 \pm 1.7$ & $8.4 \pm 2.07$ & $8.3 \pm 2.4$ \\
\hline Periphery & & $134.2 \pm 10.2$ & $168.0 \pm 10.7$ & $97.4 \pm 9.3$ & $131.2 \pm 10.3$ & $33.8 \pm 10.2$ \\
\hline \multicolumn{7}{|l|}{2 spaces } \\
\hline Fovea & & $34.4 \pm 1.3$ & $38.0 \pm 2.0$ & $1.5 \pm 1.2$ & $5.2 \pm 1.58$ & $3.7 \pm 1.1$ \\
\hline Periphery & & $128.3 \pm 8.4$ & $144.3 \pm 12.3$ & $91.5 \pm 7.7$ & $107.5 \pm 11.8$ & $16.0 \pm 11.4$ \\
\hline \multicolumn{7}{|l|}{3 spaces } \\
\hline Fovea & & $33.7 \pm 1.6$ & $36.6 \pm 1.5$ & $0.9 \pm 1.5$ & $3.7 \pm 1.8$ & $2.9 \pm 1.4$ \\
\hline Periphery & & $98.1 \pm 10.7$ & $128.7 \pm 11.5$ & $61.3 \pm 9.8$ & $92.0 \pm 11.1$ & $30.6 \pm 9.5$ \\
\hline
\end{tabular}


$[F(1,11)=84.9, p<.001]$ and stimulus type $[F(2,22)=$ $79.2, p<.001]$ and a significant interaction $[F(2,22)=$ $62.8, p<.001]$ between these variables. SD thresholds were shorter at the fovea than at the periphery. At the fovea, single letters and words required the same $\mathrm{SD}$, whereas trigrams required a significantly longer $\mathrm{SD}$. At the periphery, both the letters in words and the letters in trigrams required more time to identify than did the single letters.

In order to normalize performance and thereby make appropriate comparisons between threshold SDs at the fovea and the periphery, the ratio of the threshold SD for each stimulus type to single-letter performance is used. This allows one to control for individual variation in letter identification thresholds and look specifically at the impact of flanking letters on thresholds; these ratios are shown in Figure 2 (the logs of the ratios are used in the analyses).

A 2 (location) $\times 2$ (stimulus type: words or trigrams) ANOVA showed main effects of location $[F(1,11)=$ $198.67, p<.001]$ and stimulus type $[F(1,11)=39.70$, $p<.001]$, but no interaction between these variables $[F(1,11)<1$, n.s.]. On average, the middle letters of words required $0.98 \pm 0.04 \times$ the SD of single letters at the fovea and $3.7 \pm 0.14 \times$ the single-letter SD at the periphery. The middle letters of trigrams required $1.3 \pm$ $0.04 \times$ the SD at the fovea and 5.2 $\pm 0.08 \times$ the SD at the periphery. All but the words at the fovea were significantly different from 1.0, indicating an increase in threshold SD, relative to the letters presented alone, and, therefore, visual crowding. A comparison of threshold SDs for the middle letters of trigrams relative to the middle letters of words shows that this ratio is similar for the fovea (1.4 \pm $0.06 \times$ the SD) and the periphery $(1.4 \pm 0.09 \times$ the SD), even though there was far more visual crowding at the periphery.
The trigrams were developed from the words; they differed by only the middle letter. Given that, it is possible that the observers would be biased to respond with a letter that forms a word, especially those observers in the blocked group, where stimulus type was known. To look at this bias, the proportion of errors that formed words (e.g., responding "a" for stimulus "lsy" or " $\mathrm{k}$ " for stimulus "shy"; these will be called lexical errors) was submitted to a 2 (group: blocked or random) $\times 2$ (stimulus type: words or trigrams) $\times 2$ stimulus location (fovea or periphery) mixed-model ANOVA. None of the main effects or interactions from this analysis was significant [all $F \mathrm{~s}<3.28, p \mathrm{~s}>.100$ ]. When the stimuli were presented at the fovea, the observers made lexical errors on $17 \% \pm 3.0 \%$ of the error trials when the stimulus was a word and on $21 \% \pm 5.0 \%$ of the error trials when the stimulus was a trigram. These values were $21 \% \pm 3.3 \%$ for words and $25 \% \pm 2.3 \%$ for trigrams at the periphery. While a fairly high percentage of the errors, there was little difference across either group or stimulus type, suggesting that whatever bias observers had to respond with a letter that formed a word did not differ depending on the nature of the stimulus or the observers' a priori knowledge of stimulus type. It is also important to remember that exactly the same number of lexical errors would occur by chance across the two stimulus types. Since the flanking letters were always the same, any incorrect response that formed a word in the trigram condition would also form a word in the word condition.

Several studies have shown that mislocation errors (i.e., reporting another letter in the stimulus string) can account for some of the reduced performance in crowding tasks (Fine, 2001; Huckauf \& Heller, 2002a, 2002b). To determine whether mislocation errors varied depending on stimulus type, a 2 (group) $\times 2$ (location) $\times 2$

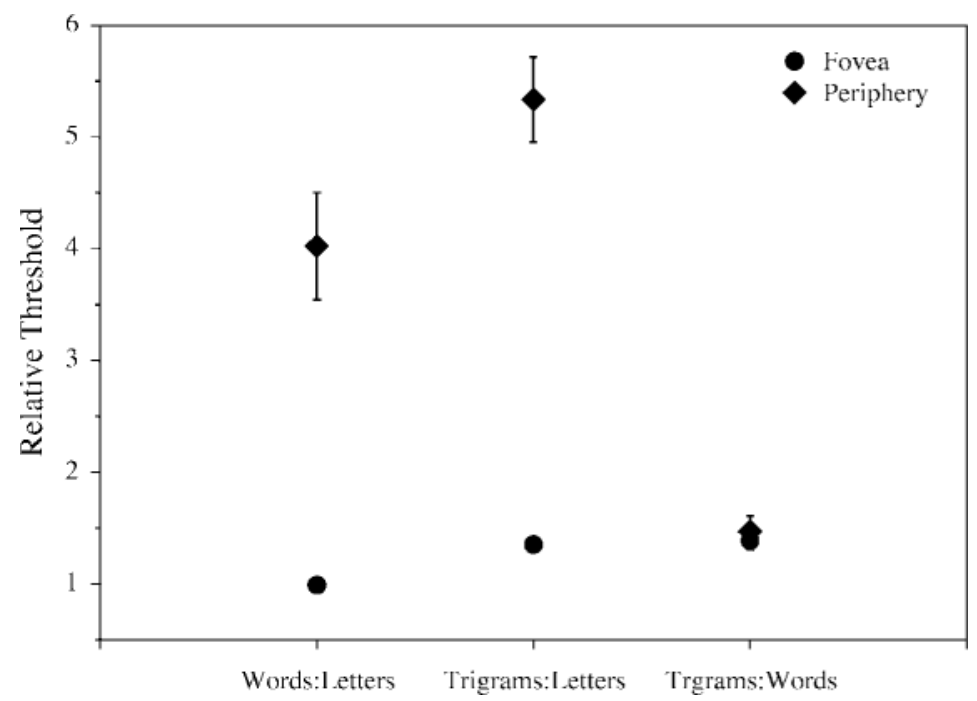

Figure 2. Relative threshold stimulus durations. Labels on the $x$-axis indicate the threshold comparisons. Filled circles are foveal thresholds; filled diamonds are peripheral thresholds. Error bars are $\pm 1 S E M$ across subjects. The dashed line indicates a ratio of 1.0 , or no difference between thresholds. 
(stimulus type) $\times 2$ (error position: left or right of the target) ANOVA was calculated. No main effects or interactions were significant, although the effect of stimulus type $[F(1,10)=4.91, p=.051]$ and the group $\times$ stimulus type interaction $[F(1,10)=3.69, p=.084]$ both approached significance. Mislocation errors occurred about $10 \%$ of the time, except for the words in the blocked group, where they occurred about $6 \%$ of the time.

\section{Discussion}

There is no question that visual crowding was more pronounced at the periphery than at the fovea, replicating several previous studies. As has been shown here, more stimulus time was needed to correctly identify flanked letters presented at the periphery, whether or not they were part of a word. Both at the fovea and at the periphery, the observers needed more time to identify the letters in the trigrams than those in the words. However, there was no difference in the relative increase in threshold SD for letters in trigrams, relative to letters in words, when they were presented at the fovea or the periphery. This finding suggests that visual crowding, which reduces stimulus quality (Fine, 2003a) and increases processing time, may have little impact on the relative benefit of word context on letter identification. These findings raise doubts regarding Massaro and Cohen's (1994) conclusion that word context has a greater impact when stimulus quality is reduced. They also raise doubts regarding Chaparro and Young's (1993; see also Ferguson, 1993; Rayner \& Bertera, 1979) conclusions regarding the specialization of the fovea for word identification and reading.

The data reported here suggest that the benefit of word context, relative to nonword letter sequences, is a constant proportion of letter identification time. That is, if we take the threshold SD for letter identification in trigrams (which is presumed to represent identification time for letters flanked by any letter-like stimuli; Fine, 2001) as the baseline identification time for flanked letters, adding word context reduces this time by a constant proportion. If this suggestion is correct, manipulating the amount of crowding should have little impact on the relative benefit of word context on the SD necessary for letter identification - that is, the ratio between threshold letter identification SD for letters within trigrams and letters within words should be constant, regardless of other stimulus manipulations. This hypothesis was tested by increasing the interletter spacing, a manipulation that is known to reduce visual crowding (Bouma, 1970; Chung et al., 2001).

\section{EXPERIMENT 2}

The impact of lateral masking and visual crowding are reduced when the flanking stimuli are moved farther from the target stimulus (Flom, 1991; Flom et al., 1963; Huckauf et al., 1999; Kooi, Toet, Tripathy, \& Levi, 1994; Loomis, 1978; Toet \& Levi, 1992; Wolford \& Chambers, 1983). In addition, as spacing increases, positional uncertainty should decrease. Eriksen and Eriksen (1974) concluded that increased spacing between letters im- proved performance in a letter search task, at least in part because it improved the observer's ability to select the target from among the distractors. This should result in fewer positional errors as spacing is increased and a further reduction in the impact of crowding (Huckauf \& Heller, 2002b). However if the conclusions drawn above are correct, there should be little or no change in the benefit of word context when crowding is reduced.

\section{Method}

Observers. Sixteen observers drawn from the same pool as that described earlier participated in this experiment. As in Experiment 1, they were divided into two groups: One saw the stimuli in blocks of trials, and the other saw the words and trigrams randomly presented in a single block.

Apparatus and Stimuli. The apparatus and stimuli were the same as those used in the previous experiment, with the following exceptions. The words and trigrams were modified so that they were shown once in each of five spacing conditions: $0.5,0,1,2$, or 3 spaces between each letter. The 0.5 spacing refers to overlapping letters. The first and third letters were shifted one-half letter space toward the target letter. The 0 -space condition refers to normal spacing. Since the stimuli were created using a fixed-width font, the letter box and, therefore, center-to-center letter spacing was constant, regardless of the letters making up the 3-letter sequence. The center-to-center distances between the target letter and the flanking letters, in degrees of visual angle, were $0.19^{\circ}, 0.38^{\circ}, 0.72^{\circ}, 1.16^{\circ}$, and $1.61^{\circ}$ at the fovea and $0.75^{\circ}, 1.5^{\circ}, 2.7^{\circ}, 4.4^{\circ}$, and $5.8^{\circ}$ at the periphery for the $0.5-, 0-, 1-, 2-$, and 3 -space conditions. The masks were expanded horizontally to cover the area required by the widest (3-space) stimuli.

Design and Procedure. The same staircase procedure as that used in Experiment 1 was used to determine threshold SDs. For all the observers, the interletter spacing was blocked, but either the stimuli were blocked or the trigrams and the words were randomly presented within each block, depending on the group. There were no other differences in the procedures for the two groups. Data collection for this experiment required about $1 \mathrm{~h}$.

\section{Results}

As before, the first two reversals of each staircase were eliminated, and the remaining reversals were averaged to define the SD threshold. As a check on the repeatability of the previous experiment, the data from that experiment were compared with those in the comparable condition in this experiment (interletter spacing $=0$ ). This 2 (experiment) $\times 2$ (location) $\times 3$ (stimulus type) mixed-model ANOVA showed no interactions between experiment and any of the other variables, although two of the interactions (experiment $x$ position and experiment $X$ location $\times$ stimulus type) were marginally significant (both $F \mathrm{~s}>2.4, p \mathrm{~s}<.108$ ). There was no difference in performance between the two experiments for the single letters $(0.1 \mathrm{msec}$ at the fovea and $0.2 \mathrm{msec}$ at the periphery). For the words, the differences were $7.3 \mathrm{msec}$ at the fovea and $16.0 \mathrm{msec}$ at the periphery; for the trigrams, these values were 20.0 and $18.6 \mathrm{msec}$.

The threshold SDs for the single letters at the fovea and the periphery again differed slightly $(4.0 \mathrm{msec}$ faster at the fovea; range, $17.0 \mathrm{msec}$ faster at the fovea to $6.7 \mathrm{msec}$ faster at the periphery), but here this difference was significant $[t(15)=2.16, p=.048]$.

The data from the 0.5 -space condition are not included in these analyses. As was pointed out by the reviewers, 


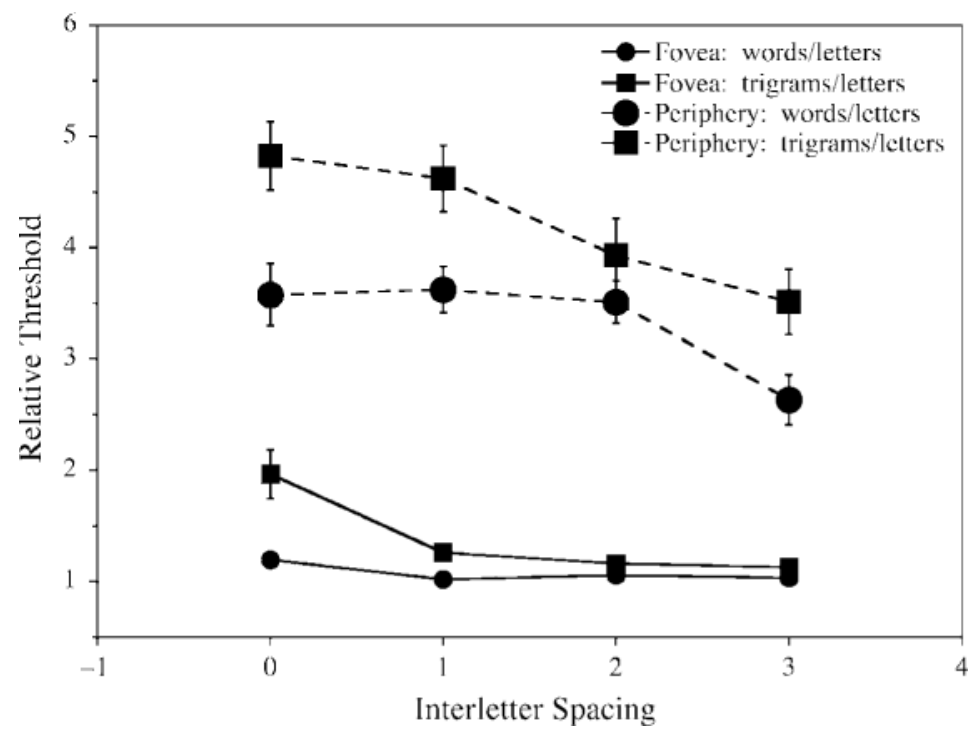

Figure 3. Threshold SD for each location (fovea [smaller symbols] or periphery [larger symbols]) $\times$ stimulus type (words [circles] or trigrams [squares]) $\times$ interletter spacing condition, relative to single letter thresholds at each location. The dashed line indicates a ratio of 1.0, or no difference between thresholds. Error bars are $\pm 1 S E M$ across subjects.

these data were near ceiling (close to the 250-msec upper limit imposed to restrict eye movements), and, therefore, may not reflect true performance. The threshold SDs for each condition are shown in Table 1 . A 2 (location) $\times 3$ (stimulus type: words or trigrams) $\times 4$ (spacing) $)^{1}$ ANOVA (collapsed across group) showed significant effects of location, stimulus type, and spacing (all $F \mathrm{~s}>25.4, p \mathrm{~s}<$ $.001)$, as well as significant interactions between location and stimulus type $[F(1,15)=7.6, p=.015]$, location and spacing $[F(3,45)=7.5, p<.001]$, and stimulus type and spacing $[F(3,45)=6.1, p=.001]$, but no three-way interaction $[F(3,45)<1$, n.s. $]$.

As in Experiment 1, the ratio of threshold SD for each condition (location $\times$ stimulus type $\times$ spacing) to threshold SD for the single letters was used in the following analyses and are shown in Figure 3. As was discussed above, this metric allows one to normalize performance across observers and conditions to baseline performance (in this case, single-letter identification at each location). Thus, the significant difference in threshold SDs between the fovea and the periphery for single letters will not affect the conclusions drawn from the data.

A 2 (group: blocked or random) $\times 2$ (location) $\times 2$ (stimulus type: words or trigrams) $\times 4$ (spacing) mixedmodel ANOVA on the log ratios showed a significant interaction between group and stimulus type $[F(1,14)=$ $5.36, p=.036]$. For the blocked group, letters in words required $2.13 \pm 0.16 \times$ the $\mathrm{SD}$ of single letters, whereas letters in trigrams required $2.95 \pm 0.24 \times$ the SD of single letters. For the random group, these values were $2.29 \pm 0.17 \times$ the SD and $2.65 \pm 0.19 \times$ the SD, respectively. This interaction was expected on the basis of a previous study (Fine, 2001), although there the primary difference in the blocked group was improved performance for the letters within words, not decreased performance for letters within trigrams.

Collapsed across group, a 2 (location) $\times 2$ (stimulus type) $\times 4$ (spacing) within-subjects ANOVA found significant interactions between location and spacing $[F(3,45)=$ $6.64, p<.001]$ and stimulus type and spacing $[F(3,45)=$ $8.09, p=.001]$ and a marginally significant three-way interaction $[F(3,45)=2.57, p=.066]$.

As we saw in Experiment 1, crowding was much more pronounced at the periphery than at the fovea $[F(1,15)=$ $312.32, p<.001]$. On average, flanked letters (words and trigrams) required about $1.23 \pm 0.04 \times$ the $\mathrm{SD}$ of single letters at the fovea and $3.78 \pm 0.11 \times$ the SD at the periphery. To control for this difference, the spacing data from each location will be treated separately. At the fovea, the stimulus type $\times$ spacing interaction was significant $[F(3,45)=10.86, p<.001]$. Relative to singleletter identification, words required 1.19, 1.02, 1.06, and $1.03 \times$ more stimulus time for the 0 - to 3 -space conditions, respectively. Only the 0 -space condition was significantly different from $1[t(15)=2.94, p=.010]$. None of the other conditions differed from 1 (all $p \mathrm{~s}>$ .166). The letters in trigrams required 1.96, 1.26, 1.16, and $1.13 \times$ more stimulus time than did the single letters. Threshold SD was significantly longer than that for single letters for the $0-, 1-$, and 2-space conditions ( $p$ s $<$ $.004)$, but the comparison for the 3 -space condition just failed to reach significance ( $p=.023$; a $p$ value of .013 is required for significance in these four-way comparisons). A comparison of threshold SD for the letters within words, relative to the letters within trigrams, showed a decrease as letter spacing increased. These threshold ratios were 
$1.63,1.27,1.10$, and $1.10 \times$ the SD for the 0 - to 3 -space conditions, respectively.

At the periphery, the interaction between stimulus type and spacing was only marginally significant $[F(3,45)=$ $2.30, p=.091]$. Relative to single-letter identification, observers required $3.58,3.62,3.51$, and $2.63 \times$ more stimulus time to identify letters within words and 4.83 , $4.62,3.93$, and $3.52 \times$ more stimulus time to identify letters within trigrams for the 0 - to 3 -space conditions, respectively. Each of these threshold SDs was longer than that required to identify single letters (all $p \mathrm{~s}<.001$ ). Direct comparison of letters in trigrams with letters in words showed that the observers required 1.42, 1.31, 1.16 , and $1.41 \times$ longer to identify the middle letters of trigrams than to identify the middle letters of words in the 0 - to 3 -space conditions, respectively. Unlike those for the fovea, these values are fairly constant. ${ }^{2}$

The comparison between the fovea and the periphery in the ratio of threshold SDs for letters within trigrams and letters within words showed no effect of location $[F(1,15)<1$, n.s.] but a significant effect of spacing $[F(3,45)=8.09, p<.001]$, as well as a marginal interaction between these variables $[F(3,45)=2.57, p=.066]$. There was a greater word benefit for the 0 -space condition than for the other spacing conditions $[F(1,45)=$ $23.36, p<.001]$. Between the fovea and the periphery, the only condition in which the difference was significant was the 3 -space condition, where there was about a $30 \%$ difference in the ratios, favoring the periphery (i.e., there was greater word benefit at the periphery for these widely spaced stimuli).

As in Experiment 1, the pattern of errors was analyzed in two ways for this experiment. For lexical errors, a 2 (group) $\times 2$ (location) $\times 2$ (stimulus type) $\times 4$ (spacing) mixed-model ANOVA showed a significant interaction between group and stimulus type $[F(1,14)=5.62, p=.033]$. In the blocked group, there was about a $4.4 \%$ difference between words (15.2\%) and trigrams (19.6\%) in the likelihood of making a lexical error. In the random group, this difference was much greater $(13 \%)$. Lexical errors for the trigrams were similar $(21.8 \%)$, but much less for words $(8.8 \%)$. These data suggest that any bias was toward selecting a letter that did not form a word. When the data from each group were analyzed separately, the blocked group showed a marginal effect of location $[F(1,7)=3.99$, $p=.086]$, with more lexical errors at the periphery than at the fovea, and a significant effect of spacing $[F(3,21)=$ $12.17, p<.001]$. The most lexical errors were made in the 0 -space condition $(24.8 \%)$, whereas there was little difference in the other spacing conditions $(15.9 \%, 15.0 \%$, and $13.9 \%$ for 1 to 3 spaces, respectively).

For the random group, there were main effects of stimulus type $[F(1,7)=32.45, p<.001]$ and spacing $[F(3,21)=7.67, p=.001]$ and a marginal interaction between these variables $[F(3,21)=2.64, p=.076]$. For the words, lexical errors accounted for $11.6 \%, 9.3 \%$, $6.4 \%$, and $8.1 \%$ of error trials for the 0 - to 3 -space conditions, respectively. For the trigrams, there were $31.0 \%$,
$18.2 \%, 20.9 \%$, and $17.0 \%$ lexical errors for the 0 - to 3 -space conditions, respectively.

Eriksen and Eriksen (1974) found improved performance in a letter search task with more space between the letters because of decreased positional uncertainty. Thus, there should be fewer mislocation errors in this task with more space between the target and the flanking letters. A 2 (location) $\times 2$ (stimulus type) $\times 4$ (spacing) ANOVA on the percentage of error trials in which the response was either the first or the third letter in the 3-letter sequence found a significant interaction between location and spacing $[F(3,45)=11.74, p<.001]$. At the fovea, position errors accounted for $22.9 \%, 21.0 \%, 18.0 \%$, and $12.8 \%$ of the error trials for the 0 - to 3 -space conditions, respectively. As spacing increased, the likelihood of selecting a response from the first or third position of the stimulus decreased. At the periphery, the fewest position errors were made with 0 spaces between the letters $(23.6 \%)$, and the most with 2 spaces between the letters $(36.7 \%)$. About the same percentage of position errors were made with 1 space and 3 spaces between the letters $(31.2 \%$ and $31.6 \%$, respectively).

One would reasonably predict that position errors would be biased toward the fovea when the stimuli are presented at the periphery. That is, there would be more responses from the third-letter position when the stimuli are presented to the left of fixation and more responses from the first-letter position when the stimuli are presented to the right of fixation. A 2 (stimulus type) $\times 4$ (spacing) $\times 2$ (position: near or far from fixation) ANOVA found a significant main effect of letter spacing $[F(3,45)=4.91, p=$ $.005]$ and marginally significant interactions between stimulus type and position $[F(1,15)=3.34, p=.087]$ and spacing and position $[F(3,45)=2.70, p=.057]$. The type $\times$ position interaction resulted from observers' selecting the letter closer to the fovea when the stimuli were trigrams $(16.3 \%$ of error trials vs. $12.9 \%$ for the letter farther from the fovea). There was little difference for the word stimuli (14.7\% for the near position and $14.5 \%$ for the far position). The spacing $\times$ position interaction was due to a difference between the 0 - and the 3 -space conditions in the far position, where observers were more likely to select the far position in the 3-space condition (17.4\%) than in the 0 -space condition ( $8.9 \%)$, opposite to the prediction. None of the other spacing conditions differed from each other in either the far or the near position.

\section{Discussion}

Increasing the interletter spacing reduced crowding at the fovea and at the periphery, as was evidenced by the decreased threshold SDs for the letters in trigrams with increased interletter spacing. The hypothesis that word context provides a constant benefit, regardless of differences in stimulus quality (at least those changes resulting from crowding) was not completely supported. At the fovea, increased interletter spacing reduced the benefit of word context. At the periphery, the benefit of word context was fairly constant, even though visual 
crowding was reduced. The decrease in word benefit at the fovea may reflect a "floor" effect. With increased spacing, the letters within both trigrams and words were identified with a threshold SD similar to that for the letters presented alone. Since the paradigm used here does not appear to show an advantage for letters presented in words, relative to letters presented alone, it is possible that the observers simply could not identify letters with less stimulus information, regardless of the context. At the periphery, where threshold SDs for flanked letters never approached those for letters presented alone, the word advantage was constant and was similar to the advantage seen for the closer spacing at the fovea.

The finding that threshold SD at the periphery for flanked letters never approached that for letters presented alone was surprising. Previous studies have shown that the effect of crowding decreases as the spacing between the target and the flanks increases and that, beyond $0.5 \times$ the eccentricity of the target, crowding is minimal (Bouma, 1970; Chung et al., 2001; Toet \& Levi, 1992). Even with more than $0.5 \times$ eccentricity between the target $\left(10^{\circ}\right)$ and the flanking letters $\left(5.8^{\circ}\right.$ in the 3 -space condition), threshold SD remained well above that for single letters in the present study. The task used here was quite different from the tasks used in previous crowding studies, although the stimuli were similar to Bouma's (1970). In his study, observers identified letters presented for $200 \mathrm{msec}$. At the $10^{\circ}$ test distance, single-letter performance (and performance for flank-to-target distances of $0.5 \times$ eccentricity or greater) was about $45 \%$ correct. The stimuli in Bouma's (1970) study were not scaled for eccentricity, whereas the stimuli used here were. This may account for our different results, since Strasburger et al. (1991) have found that both the size of the flank and its distance from the target affect crowding (although see Tripathy \& Cavanagh, 2002, for data that suggest otherwise).

The pattern of lexical errors differed from that in the first experiment. Here, there was a significant effect of group (blocked or random) on the probability of making a lexical error. However, it was not in the direction one might predict. There was little difference in the percentage of lexical errors when the stimuli were blocked, but the observers made fewer lexical errors on the word stimuli in the random group. Interestingly, although the percentage of lexical errors for words decreased with increased spacing, the decrease was somewhat greater for the trigrams. This might suggest that as the interletter spacing increased, the "wordness" of the stimulus decreased. However, if this were the case, there is no reason to expect spacing to have a similar (blocked) or somewhat greater (random) impact on trigrams.

As was predicted from the work of Eriksen and Eriksen (1974), position errors were reduced at the fovea as interletter spacing increased. The same was not true at the periphery. This was not due to the observers' selecting the closest (and therefore most visible) letter. In fact, with the widest spacing, the observers were more likely to select the letter farther from fixation. It is unclear what, if any, impact this may have had on the conclusions drawn from the data, since there was little difference in position errors between the word and the trigram stimuli.

\section{GENERAL DISCUSSION}

Using relative SD thresholds, the experiments reported here show, as have others, that letter identification is more difficult when the target letter is surrounded by other letters, more so at the periphery than at the fovea. These experiments also confirm that letters are identified more easily when they are part of a word than when they are part of a nonword letter sequence. These experiments have also shown that the advantage in letter identification derived from word context is constant at different retinal locations and is fairly constant with different stimulus qualities (more and less visual crowding). These findings are contrary both to the conclusions of those investigators who have claimed an advantage for word processing when the stimuli are presented at the fovea (Chaparro \& Young, 1993; Ferguson, 1993; Rayner \& Bertera, 1979) and to Massaro and Cohen's (1994) supposition that reduced stimulus quality will increase the benefit of word context. These findings also suggest that increased processing time (i.e., longer threshold SDs) does not necessarily lead to an increase in the benefit of word context, as is predicted by McClelland and Rumelhart's (1981; Rumelhart \& McClelland, 1982) interactive activation model of letter processing.

The task used here for determining letter identification performance in words and nonwords is quite different from that used in most studies of visual crowding and in studies in which the role of word context on letter identification has been investigated. Studies of visual crowding generally compare single- and flanked letter identification for a fixed SD (although see recent studies by Fine, 2003b, and Tripathy \& Cavanagh, 2002, where $\mathrm{SD}$ was manipulated). Classic studies of word context (e.g., Massaro \& Klitzke, 1979; McClelland \& Rumelhart, 1981; Reicher, 1969; Rumelhart \& McClelland, 1982; Wheeler, 1970) primarily used the difference in percentage correct for a two-alternative forced choice task and a constant SD to determine word benefit. It is difficult to compare the degree of visual crowding found here with that in other studies in which percentage correct was compared. However, the data reported here are in line with those reported elsewhere where percentages correct for letters within words and letters within nonwords were compared for different SDs. The staircase used here to determine threshold SD was designed to converge on approximately $78 \%$ correct performance. Using this criterion and the data presented in Figure 4 of Massaro and Cohen (1994), the estimated SD threshold is $93.3 \mathrm{msec}$ for letters in nonwords and $65.1 \mathrm{msec}$ for letters in words, a ratio of $1.4 \times$. A similar analysis of the data from Figure 4 of Grainger and Jacobs (1994) shows thresholds of $32.3 \mathrm{msec}$ for letters in nonwords and $24.7 \mathrm{msec}$ for letters in words, a ratio of $1.3 \times$. Both of these studies used the more traditional two-alternative forced choice paradigm, but varied the SD. 
The two experiments reported here, as well as the data in Massaro and Cohen (1994) and Grainger and Jacobs (1994), all suggest that observers require about $1.4 \times$ as much inspection time to identify letters within nonword letter strings as they do letters within words. The data reported here suggest that this is true regardless of retinal location (fovea or periphery) or the degree of visual crowding. No difference in the benefit of word context between the fovea and the periphery is inconsistent with other reports (Chaparro \& Young, 1993; Ferguson, 1993; Rayner \& Bertera, 1979). However, none of those studies compensated for the reduced resolution of the retinal periphery by increasing letter size. When letter size has been appropriately magnified, it has been found that sentence context is as beneficial at the periphery as it is at the fovea (Fine et al., 1999; Fine \& Peli, 1996).

Obviously, had the absolute difference in SD threshold been used as the dependent measure in these comparisons, a different story would have emerged. The difference between letter identification thresholds in trigrams and in words was much greater at the periphery than at the fovea (see Table 1). From this, one would have to conclude that there is more word benefit for letters presented at the periphery than for letters presented at the fovea. But this does not take into account individual observer or group differences in performance. Although there was no statistical difference between Experiments 1 and 2 in the 0 -space condition, the difference between the thresholds for trigrams and words at the fovea was about $2 \times$ larger in Experiment 2 . This suggests that the benefit of word context was twice as large in Experiment 2 as it was in Experiment 1 for the fovea; yet for these same observers, there was no difference in word benefit at the periphery. This conclusion is clearly spurious and provides strong justification for the use of relative changes in threshold SD when these comparisons are made.

That the amount of visual crowding had little effect on the benefit of word context was particularly surprising, given the number of studies that have shown the advantages of context when stimulus quality is reduced, as it is for flanked letters (Fine, 2003a). It could be argued that the visual crowding induced here did not sufficiently diminish the quality of the stimuli. This is not likely, since the observers required significantly more time to identify the letters when they were flanked by other letters at both the fovea and the periphery. In addition, a recent experiment (Fine, 2003a) has shown substantially reduced contrast sensitivity for flanked letters, relative to single letters, at much smaller eccentricities. Future studies are required to determine whether the consistent benefits of word context hold with other forms of stimulus degradation.

\section{REFERENCES}

Bouma, H. (1970). Interaction effects in parafoveal letter recognition. Nature, 226, 177-178.

Bouma, H. (1973). Visual interference in the parafoveal recognition of initial and final letters of words. Vision Research, 13, 767-782.

Cavanagh, P. (2001). Seeing the forest but not the trees. Nature Neuroscience, 4, 673-674.
Chaparro, A., \& Young, R. S. L. (1993). Reading with rods: The superiority of central vision for rapid reading. Investigative Ophthalmology \& Visual Science, 34, 2341-2347.

CHUng, S. T., LEVI, D. M., \& LEGGe, G. E. (2001). Spatial-frequency and contrast properties of crowding. Vision Research, 41, 1833-1850.

ERIKSEN, B. A., \& ERIKSEN, C. W. (1974). Effects of noise letters upon the identification of a target letter in a nonsearch task. Perception \& Psychophysics, 16, 143-149.

FARRELl, J. E., \& DeSMARAIS, M. (1990). Equating character-identification performance across the visual field. Journal of the Optical Society of America A, 7, 152-159.

Ferguson, E. D. (1993). Motivational influences on word recognition: IV. Cortical magnification does not explain parafoveal versus foveal differences. Bulletin of the Psychonomic Society, 31, 602-604.

FINE, E. M. (2001). Does meaning matter? The impact of word knowledge on lateral masking. Optometry \& Vision Science, 78, 831-838.

Fine, E. M. (2003a, May). Reduced contrast does not reduce visual crowding. Poster presented at the 3rd Annual Vision Sciences Meeting, Sarasota, FL.

FINE, E. M. (2003b). Visual crowding in older adults. Manuscript submitted for publication.

Fine, E. M., Hazel, C. A., Petre, K. L., \& Rubin, G. S. (1999). Are the benefits of sentence context different in central and peripheral vision? Optometry \& Vision Science, 76, 764-769.

Fine, E. M., \& PELI, E. (1996). The role of context in reading with central field loss. Optometry \& Vision Science, 73, 533-539.

Flom, M. C. (1991). Contour interaction and the crowding effect. Problems in Optometry, 3, 237-257.

Flom, M. C., Weymouth, F. W., \& Kahneman, D. (1963). Visual resolution and contour interaction. Journal of the Optical Society of America, 53, 1026-1032.

FRANCIS, W. N., \& KUČERA, H. (1982). Frequency analysis of English usage: Lexicon and grammar. Boston: Houghton Mifflin.

GARCíA-PÉREZ, M. A. (1998). Forced-choice staircases with fixed step sizes: Asymptotic and small-sample properties. Vision Research, $\mathbf{3 8}$, 1861-1881.

GRAINGER, J., \& JACOBS, A. M. (1994). A dual read-out model of word context effects in letter perception: Further investigations of the word superiority effect. Journal of Experimental Psychology: Human Perception \& Performance, 20, 1158-1176.

HuCKAUF, A., \& Heller, D. (2002a). Spatial selection in peripheral letter recognition: In search of boundary conditions. Acta Psychologica, 111, 101-123.

HUCKAUf, A., \& Heller, D. (2002b). What various kinds of errors tell us about lateral masking effects. Visual Cognition, 9, 889-910.

Huckauf, A., Heller, D., \& Nazir, T. A. (1999). Lateral masking: Limitations of the feature interaction account. Perception \& Psychophysics, 61, 177-189.

INTRILIGATOR, J., \& CAVANAGH, P. (2001). The spatial resolution of visual attention. Cognitive Psychology, 43, 171-216.

JACOBS, R. J. (1979). Visual resolution and contour interaction in the fovea and periphery. Vision Research, 19, 1187-1195.

KaERnBaCH, C. (1991). Simple adaptive testing with the weighted up-down method. Perception \& Psychophysics, 49, 227-229.

Kooi, F. L., Toet, A., Tripathy, S. P., \& LeVI, D. M. (1994). The effect of similarity and duration on spatial interaction in peripheral vision. Spatial Vision, 8, 255-279.

LATHAM, K., \& WhitaKer, D. (1996). Relative roles of resolution and spatial interference in foveal and peripheral vision. Ophthalmic \& Physiological Optics, 16, 49-57.

LEAT, S. J., LI, W., \& EPP, K. (1999). Crowding in central and eccentric vision: The effects of contour interaction and attention. Investigative Ophthalmology \& Visual Science, 40, 504-512.

LoOMIS, J. M. (1978). Research note: Lateral masking in foveal and eccentric vision. Vision Research, 18, 335-338.

Massaro, D. W., \& Cohen, M. M. (1994). Visual, orthographic, phonological, and lexical influences in reading. Journal of Experimental Psychology: Human Perception \& Performance, 20, 1107-1128.

MAssaro, D. W., \& KLitzKe, D. (1979). The role of lateral masking and orthographic structure in letter and word recognition. Acta Psychologica, 43, 413-426. 
McClelland, J. L., \& Rumelhart, D. E. (1981). An interactive activation model of context effects in letter perception: Pt. 1. An account of basic findings. Psychological Review, 88, 375-407.

NAZIR, T. A. (1992). Effects of lateral masking and spatial precueing on gap-resolution in central and peripheral vision. Vision Research, $\mathbf{3 2}_{2}$ 771-777.

RAYNER, K., \& BERTERA, J. H. (1979). Reading without a fovea. Science, 206, 468-469.

REICHER, G. M. (1969). Perceptual recognition as a function of meaningfulness of stimulus material. Journal of Experimental Psychology, 81, 275-280.

RUMElhart, D. E., \& McClelland, J. L. (1982). An interactive activation model of context effects in letter perception: Pt. 2. The contextual enhancement effect and some tests and extensions of the model. Psychological Review, 89, 60-94.

Strasburger, H., Harvey, L. O., JR., \& Rentschler, I. (1991). Contrast thresholds for identification of numeric characters in direct and eccentric view. Perception \& Psychophysics, 49, 495-508.
Toet, A., \& Levi, D. M. (1992). The two-dimensional shape of spatial interaction zones in the parafovea. Vision Research, 32, 1349-1357. Tripathy, S. P., \& Cavanagh, P. (2002). The extent of crowding in peripheral vision does not scale with target size. Vision Research, $\mathbf{4 2}_{2}$ 2357-2369.

WHEELER, D. D. (1970). Processes in word recognition. Cognitive Psychology, 1, 59-85.

Wolford, G., \& Chambers, L. (1983). Lateral masking as a function of spacing. Perception \& Psychophysics, 33, 129-138.

\section{NOTES}

1. Since single-letter performance could be assessed only with one "spacing," those data are not included in this analysis.

2 . The dip in the 2 -space condition was due primarily to a single observer, who required almost $3 \times$ more stimulus time for the 2 -space condition than for the 3-space condition for words. Without this observer's data, the ratios for the 0 - to 3 -space conditions are $1.38,1.33,1.21$, and $1.41 \times$, respectively.

APPENDIX

\begin{tabular}{|c|c|c|c|c|c|}
\hline Base Letter & Word & Trigram & Base Letter & Word & Trigram \\
\hline \multirow[t]{3}{*}{$\mathrm{a}$} & lap & lsp & $\mathrm{n}$ & one & oue \\
\hline & wag & wsg & & ink & iuk \\
\hline & lay & lsy & & any & auy \\
\hline \multirow[t]{3}{*}{ c } & ace & aoe & o & hoe & hme \\
\hline & act & aot & & $\operatorname{cog}$ & $\mathrm{cmg}$ \\
\hline & ice & ioe & & wok & wmk \\
\hline \multirow[t]{3}{*}{ d } & ado & afo & $\mathrm{p}$ & ape & aje \\
\hline & ode & ofe & & spy & sjy \\
\hline & ads & afs & & apt & ajt \\
\hline \multirow[t]{3}{*}{$\mathrm{e}$} & yew & $\mathrm{ycw}$ & $\mathrm{r}$ & ark & avk \\
\hline & yet & yct & & ore & ove \\
\hline & net & nct & & wry & wvy \\
\hline \multirow[t]{3}{*}{$\mathrm{f}$} & aft & aht & $\mathrm{s}$ & ask & ank \\
\hline & ifs & his & & ash & anh \\
\hline & oft & oht & & use & une \\
\hline \multirow[t]{3}{*}{$\mathrm{g}$} & age & aqe & $\mathrm{t}$ & ate & abe \\
\hline & ago & aqo & & sty & sby \\
\hline & ego & eqo & & its & ibs \\
\hline \multirow[t]{3}{*}{$\mathrm{h}$} & thy & tly & $\mathrm{u}$ & out & oet \\
\hline & who & wlo & & jug & jeg \\
\hline & she & sle & & sum & sem \\
\hline \multirow[t]{3}{*}{$\mathrm{i}$} & rib & $\mathrm{rtb}$ & $\mathrm{w}$ & owe & oze \\
\hline & pin & ptn & & owl & ozl \\
\hline & sip & stp & & two & tzo \\
\hline \multirow[t]{3}{*}{1} & sly & siy & $\mathrm{y}$ & bye & bpe \\
\hline & elf & eif & & rye & rpe \\
\hline & old & oid & & gym & gpm \\
\hline \multirow[t]{3}{*}{$\mathrm{m}$} & amp & awp & & & \\
\hline & emu & ewu & & & \\
\hline & ump & uwp & & & \\
\hline
\end{tabular}

(Manuscript received January 9, 2001;

revision accepted for publication October 5, 2003.) 